\title{
Glycolysis and Respiration in Yeasts: the Effect of Ammonium Ions Studied by Mass Spectrometry
}

\author{
By DAVID LLOYD, ${ }^{*} \uparrow$ BODIL KRISTENSEN AND HANS DEGN \\ Institute of Biochemistry, Odense University, Campusvej 55, DK-5230 Odense M, Denmark
}

\author{
(Received 2 February 1983; revised 5 March 1983)
}

\begin{abstract}
Addition of $\mathrm{NH}_{4}^{+}$in the presence of glucose to washed suspensions of Saccharomyces uvarum, Schizosaccharomyces pombe or Candida utilis greatly increased glycolytic $\mathrm{CO}_{2}$ production and slightly stimulated respiration. In all three organisms the ammonium ion effect was distinguishable from the effect of an uncoupler of aerobic energy conservation (carbonyl cyanide $m$-chlorophenylhydrazone; CCCP). The Pasteur effect (aerobic inhibition of glycolysis) in the fermentative yeasts also proceeded independently of the ammonium ion effect. Possible control mechanisms are discussed.
\end{abstract}

\section{INTRODUCTION}

The Pasteur effect (inhibition by $\mathrm{O}_{2}$ of the utilization of carbohydrates: Krebs, 1972) involves the integration of several feedback mechanisms; especially important are the allosteric effectors of phosphofructokinase. This enzyme is inhibited by ATP and citrate, and activated by AMP, $\mathrm{P}_{\mathrm{i}}, \mathrm{NH}_{4}^{+}$and $\mathrm{K}^{+}$(Ramaiah et al., 1964; Salas et al., 1965; Mavis \& Stellwagen, 1970). In this report we show that the addition of $\mathrm{NH}_{4}^{+}$to washed non-proliferating cell suspensions of yeasts stimulates glycolysis; this 'ammonium ion effect' is quite distinct from the stimulatory effect of CCCP and from the Pasteur effect.

\section{METHODS}

Organisms and culture conditions. Candida utilis NCYC 193 was maintained and grown on defined medium containing $1 \%$ (w/v) glucose as described previously (Kader \& Lloyd, 1979). Saccharomyces uvarum (formerly $S$. carlsbergensis) NCYC 745 and Schizosaccharomyces pombe $972 \mathrm{~h}^{-}$were maintained on $10 \%$ glucose/malt extract/agar slopes and grown on defined medium containing $1 \%$ glucose as described by Mitchison (1970), but with $0.5 \%\left(\mathrm{NH}_{4}\right)_{2} \mathrm{SO}_{4}$ as nitrogen source. All three yeasts were grown at $30^{\circ} \mathrm{C}$ with rotary shaking (100 r.p.m.) as $200 \mathrm{ml}$ cultures in $500 \mathrm{ml}$ conical flasks. Organisms were counted in a Thoma haemocytometer slide (Hawkesly, Lancing, Sussex, U.K.) after suitable dilution. They were harvested by centrifugation at $2000 \mathrm{~g}$ for $2 \mathrm{~min}$ at $4{ }^{\circ} \mathrm{C}$, washed twice in $20 \mathrm{vol}$. of $15 \mathrm{mM}-\mathrm{NaCl}$ and finally resuspended in $5 \mathrm{vol}$. of this solution.

Measurement of $\mathrm{O}_{2}$ and $\mathrm{CO}_{2}$ by mass spectrometry. Concentrations of $\mathrm{O}_{2}$ and $\mathrm{CO}_{2}$ were measured in yeast suspensions $(4.5 \mathrm{ml}$ in $10 \mathrm{~mm}$-sodium citrate buffer, $\mathrm{pH} 4.0)$ in a thermostated open reaction vessel of $7 \mathrm{ml}$ total volume using a quadrupole mass spectrometer type Q8 (VG Micromass, Winsford, Cheshire, U.K.) fitted with a turbopump type TPN 100 (A. Pfeiffer Vacuum Tecknic, D-6334 Asslar, F.R.G.). Similar results were obtained with other buffers, suggesting that the cells are not permeable to citrate. Details of the equipment have been described previously (Lloyd et al., 1981). Mass per charge numbers 32 and 44 were scanned for $\mathrm{O}_{2}$ and $\mathrm{CO}_{2}$ respectively; half times for equilibration correspond to transfer constants of $7.2 \times 10^{-3} \mathrm{~s}^{-1}$ and $5.8 \times 10^{-3} \mathrm{~s}^{-1}$ respectively and the scanning cycle was $0.3 \mathrm{~s}$. The gas phase was controlled by a calibrated digital gas mixer (Lundsgaard \& Degn, 1973). Steady-state rates of $\mathrm{O}_{2}$ consumption and $\mathrm{CO}_{2}$ evolution were calculated from steadystate concentrations (Degn et al., 1980). The concentration of $\mathrm{O}_{2}$ in the buffer in equilibrium with atmospheric air was assumed to be $240 \mu \mathrm{M}$. $\mathrm{CO}_{2}$ measurement was calibrated by the injection of small amounts of $100 \mathrm{~mm}-$ $\mathrm{NaHCO}_{3}$ into the buffer in the reaction vessel.

$\uparrow$ Permanent address (for correspondence): Department of Microbiology, University College, Newport Road, Cardiff CF2 1TA, U.K.

Abbreviation: CCCP, carbonyl cyanide $m$-chlorophenylhydrazone. 


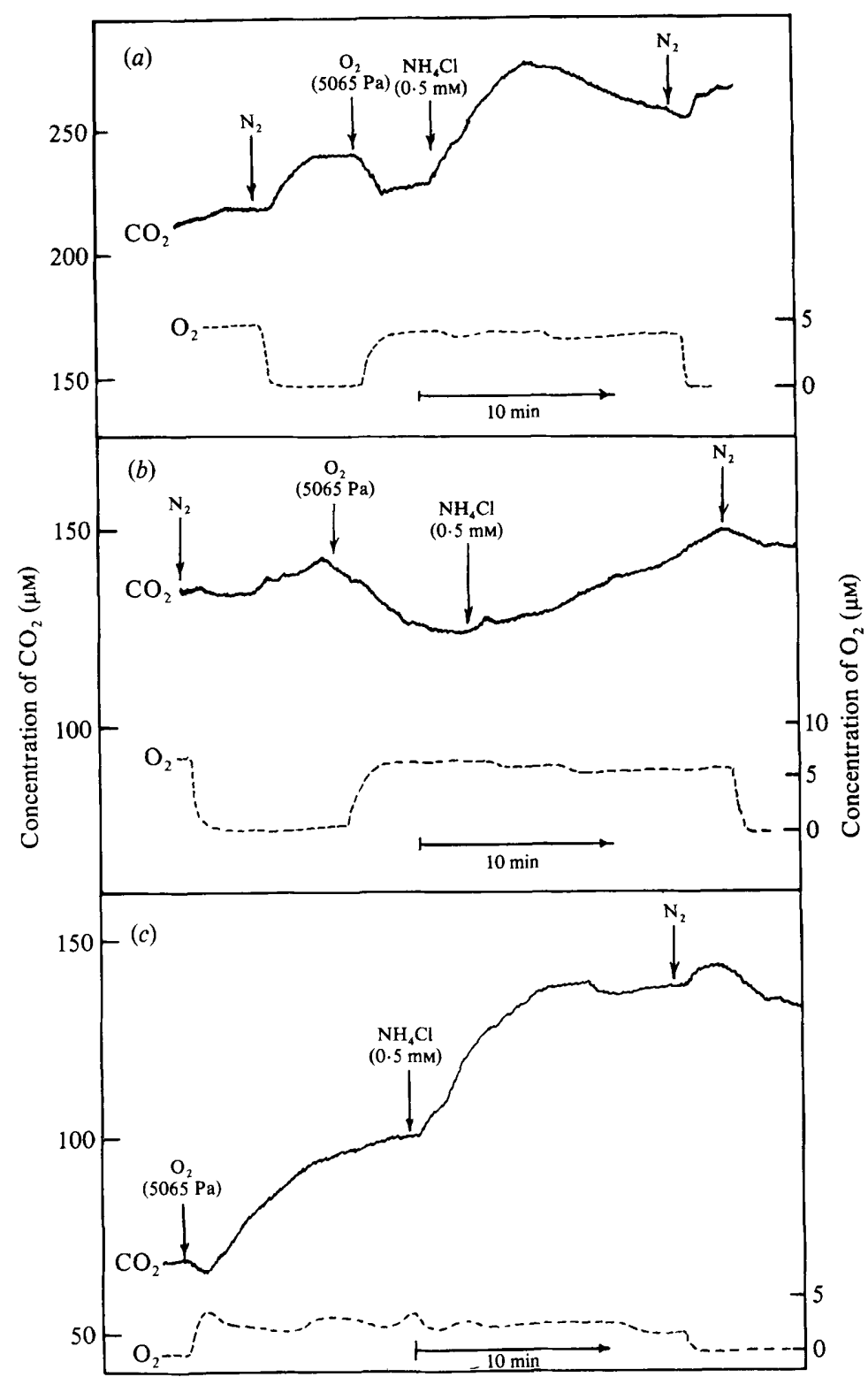

Fig. 1. $\mathrm{O}_{2}$ and $\mathrm{CO}_{2}$ concentrations in washed cell suspensions of yeast: effect of ammonium ions. (a) Saccharomyces uvarum, (b) Schizosaccharomyces pombe, $(c)$ Candida utilis. Cell concentrations in the cultures at harvesting were $2 \times 10^{8}, 8 \times 10^{7}, 2 \times 10^{8}$ and in the reaction vessel $1.6 \times 10^{8}, 8 \times 10^{7}$, $5 \times 10^{7}$ in $(a),(b)$ and $(c)$ respectively; 11 mM-glucose was present throughout. At arrows additions were made or the composition of the gas stream entering the open system was altered as indicated. ----, $\mathrm{O}_{2}$ (mass 32$) ;-, \mathrm{CO}_{2}$ (mass 44$)$.

\section{RESULTS AND DISCUSSION}

Figure 1 demonstrates the ammonium ion effect in the three yeasts. In the presence of $11 \mathrm{mM}$ glucose, switching the gas phase from $5 \% \mathrm{O}_{2}$ to $\mathrm{N}_{2}$ stimulated $\mathrm{CO}_{2}$ evolution, and the effect (Pasteur effect) was reversible. In Saccharomyces uvarum (Fig. 1 a) addition of $0.5 \mathrm{mM}-\mathrm{NH}_{4} \mathrm{Cl}$ (final concn) to the aerobic suspension gave a more pronounced stimulation of $\mathrm{CO}_{2}$ evolution, which reached a maximum after about $5 \mathrm{~min}$. Respiration was also slightly stimulated $(<5 \%)$. 
Before $\mathrm{CO}_{2}$ concentration had returned to its initial value the Pasteur effect was still demonstrable as a stimulation of $\mathrm{CO}_{2}$ production on making the suspension anaerobic. Addition of $\mathrm{NH}_{4} \mathrm{Cl}$ anaerobically gave a burst of $\mathrm{CO}_{2}$ evolution (not shown). Stimulation of glycolysis and respiration by an uncoupler of aerobic energy conservation (CCCP) was observed before or after addition of $\mathrm{NH}_{4} \mathrm{Cl}$ (not shown). The ammonium ion effect was also observed in Schizosaccharomyces pombe (Fig. 1 ), and in Candida utilis (Fig. 1c), although the Pasteur effect was not evident in the latter. Control experiments indicated the specificity of stimulation by $\mathrm{NH}_{4}^{+}$; thus addition of $0.5 \mathrm{mM}-\mathrm{NaCl}$ produced no response, whereas $0.5 \mathrm{mM}-\mathrm{NH}_{4} \mathrm{OH}$ in potassium phosphate buffer gave similar effects to those observed for $\mathrm{NH}_{4} \mathrm{Cl}$.

A possible explanation for the ammonium ion effect lies in the activation of phosphofructokinase (Mavis \& Stellwagen, 1970); consumption of ammonium ions to produce amino acids and proteins may explain the transient nature of the effect. That the effects of anaerobiosis, uncoupler and ammonium ions are additive suggests that maximal activation of phosphof ructokinase requires a combination of circumstances. Increased respiration in the presence of $\mathrm{NH}_{4}^{+}$ may reflect increased energy demand for transport or biosynthetic reactions. These observations may be related to those of Devine \& Slaughter (1980) who reported that ethanol production was accelerated in media containing high concentrations of ammonium ions.

\section{REFERENCES}

Degn, H., Lundsgaard, J. S., Petersen, L. C. \& ORMICKI, A. (1980). Polarographic measurement of steady state kinetics of oxygen uptake by biochemical samples. Methods of Biochemical Analysis 26, 4777.

Devine, S. J. \& Slaughter, J. C. (1980). Effect of medium composition on the production of ethanol by Saccharomyces cerevisiae. FEMS Microbiology Letters 9, 19-21.

KADER, J. \& LLOYD, D. (1979). Respiratory oscillations and heat evolution in synchronous cultures of Candida utilis. Journal of General Microbiology 114, 455-461.

Krfas, H. A. (1972). The Pasteur effect and the relations between respiration and fermentation. In Essays in Biochemistry, vol. 8, pp. 1-27. Edited by P. N. Campbell \& F. Dickens. London: Academic Press.

Lloyd, D., Kristensen, B. \& DeGN, H. (1981). Oxidative detoxification of hydrogen sulphide de- tected by mass spectrometry in the soil amoeba Acanthamoeba castellanii. Journal of General Microbiology 126, 167-170.

Lundsgaard, J. S. \& Degn, H. (1973). Digital regulation of gas flow rates and composition of gas mixtures. IEEE Transactions on Biomedical Engineering BME-20, 384-387.

Mavis, R. D. \& Stellwagen, E. (1970). Role of cations in yeast phosphof ructokinase catalysis. Journal of Biological Chemistry 245, 674-680.

MrTCHISON, J. M. (1970). Physiological and cytological methods for Schizosaccharomyces pombe. Methods in Cell Physiology 4, 131-165.

Ramaiah, A., Hathaway, J. A. \& Atkinson, D. E. (1964). Adenylates as a metabolic regulator. Journal of Biological Chemistry 239, 3619-3622.

Salas, M. L., Vinuela, E., Salas, M. \& Sols, A. (1965). Citrate inhibition of phosphofructokinase and the Pasteur effect. Biochemical and Biophysical Research Communications 19, 371-376. 